\title{
Adapting the SCOR Model to Suit the Different Scenarios: A Literature Review \& Research Agenda
}

\author{
Fasika.Bete Georgise (Corresponding author) \\ International Graduate School for Dynamics in Logistics (IGS), University of Bremen \\ Bremen Institute for Production and Logistics-BIBA GmbH \\ Hochschulring 20, D-28359 Bremen, Germany \\ E-mail: geo@biba.uni-bremen.de
}

Klaus-Dieter Thoben

Bremen Institute for Production and Logistics-BIBA GmbH

Faculty of Production Engineering, University of Bremen

Hochschulring 20, D-28359 Bremen, Germany

E-mail: tho@biba.uni-bremen.de

Marcus Seifert

Bremen Institute for Production and Logistics-BIBA GmbH

Faculty of Production Engineering, University of Bremen

Hochschulring 20, D-28359 Bremen, Germany

E-mail: sf@biba.uni-bremen.de

$\begin{array}{ll}\text { Received: November 16, } 2011 & \text { Accepted: December 14, } 2011 \quad \text { Published: March 16, } 2012 \\ \text { doi:10.5539/ijbm.v7n6p2 } & \text { URL: http://dx.doi.org/10.5539/ijbm.v7n6p2 }\end{array}$

The research is financed by Engineering Capacity Building Program (Ethiopia).

\begin{abstract}
The importance of the supply chain modeling and improving has long been recognized as one of competitiveness strategy in scientific research. However, most of the performed work has focused on designing supply chain modeling and improving in developed countries with fewer concerns for their partners in developing countries. The manufacturing industry in developing countries has experienced fierce competition for their product and consequently, a loss of market share. The Supply-Chain Operations Reference (SCOR) provides a standard description of supply chain processes, performance metrics, best practice and enabling technologies. It offers a comprehensive methodology to improve supply chain operations. It is designed by the Supply-Chain Council (SCC). It is widely acknowledged as the quasi-industry standard for supply chain management. This paper presents a literature review of published material so far relating to SCOR model adaptation. The results of SCOR model adaptation for six different application works are reviewed $\&$ discussed for future research.
\end{abstract}

Keywords: SCOR model, Developing countries, Manufacturing industry, Model adaptation

\section{Introduction}

Developing countries are becoming more and more integrated in the global manufacturing supply chain due to international nature of the production and retail. A consumer who visits a market in Berlin, Rome, Paris or Amsterdam, can find fashion clothes from Bangladesh and Pakistan, special coffees from Tanzania, Ethiopia or Kenya, or rice from Thailand, besides many other imported items from a number of developing countries. The manufacturing industry in developing countries (MIDC) has been already a part of global supply chains for a long time as the raw material supplier and also manufacturer of the final product (see Figure 1). Even though the MIDC plays an important role as the supplier and as the producer, the MIDC has not received enough attention 
and has not been studied well. At the same time, it has faced challenges in highly competitive markets. In this market, all manufacturers try to improve their product quality, reduce a cost and reduce their product delivery lead time to compete in the global market.

\section{Insert Figure 1-here}

However, the MIDC still has been practices a backward and an independent performance evaluation on intra-organizations assessments (Abdelsalam, 2009; Wall, 2007; Abdel Aziz, 2005). Traditionally, the focus of performance measurement has been on process operations within the organizational boundaries. In today's competitive environment, it is supply chains (SC) rather than companies that compete (Fynes et al. 2005; Christopher and Towill, 2001). A significant competitive advantage cannot be obtained by improving the efficiency of products and processes alone; the MIDC need to improve the efficiency of product, process, and SC (Fine, 1998; Olhager and Selldin, 2004). In recent years, the importance of process models, performance measures and best practices has been recognized as one of the major problems in process evaluation and improvement of the supply chains in the MIDC (Abdelsalam, 2009; Deloitte, 2009; Irfan, 2008; Magder, 2005).

The state-of-the-art techniques and practices currently in operation in developed countries companies can undoubtedly be of great benefit to organizations in developing countries. However, the techniques and practices which have evolved in the context of Western environment should not be transplanted as they are onto the socio-cultural environments of developing countries. The performance measurement such as Balanced Scorecard (BSC), Supply-Chain Operations Reference (SCOR) model can be regarded as one of those theories whose validity needs to be tested in a developing country's context, as this context can be completely different from developed countries'. Direct application of the SCOR model to developing countries is not advisable and may not be wholly satisfactory due to variations in environmental factors and conditions. Shewchuk (1998) says that "one size does not fit all," meaning there's a necessity to find the most fitting supply chain management approach \& model tailored to the specific business process and its environment in which a firm is operating (Castelli, 2006). Currently, there are some research initiatives for such a kind of adaptation and adoption in BSC in developing countries (Kassahun, 2010, Holmes et al. 2006).

There is a growing body of literature on the modernization of manufacturing activities, business management and information systems in developing countries, with an emphasis on management accounting and performance measurement practice (Kassahun, 2010; Abdelsalam, 2009; Deloitte, 2009; Irfan, 2008; Holmes et al. 2006; Magder, 2005;). Nonetheless, the recent academic and professional literature, specifically on the performance measurement system in developing countries is limited. (Abdel Aziz et al., 2005). The popularity of the balanced scorecard (BSC) is gradually changing this, mainly in Asian countries, but it is still a relatively new concept for developing countries (Waal, 2007). Although performance measurements are relatively unknown in many African countries, the interest in such an improvement tool is growing among some organizations and in specific countries. However, there is some promising initiation on some countries, especially on implementation of BSC like Burkina Faso, Egypt, Zimbabwe, South Africa, Kenya and Ethiopia (Waal, 2007). Some of the countries have the advantage that it hosts many transnational companies, which are already applying the latest performance measurement. It has to be noted that quite a few scholars doubt whether existing developed countries management practices can and will work in developing and emerging markets, and it has long been recognized that culture is a major source of differences in measurement and reporting standards and methods.

In this paper, we present a literature review on the SCOR model adaptation. The overall aim is to provide the framework to understand and take a lesson on this model adaptation process that has done in the past literature as well as highlights a research agenda for the DCMI scenario. More specifically the objectives of this paper are:

- Explain the challenges \& barriers for supply chains to the MIDC

- Revise the SCOR model adaptation to different environments

- Brief the research methods and approach followed in previous research

- Indicate the direction for future research for the SCOR model adaption

The rest of paper is arranged as follows. Next to the introduction, we discuss the SCOR model overview. Then, developing countries challenges and barriers of supply chains are presented. The fifth section will discuss the literature review on SCOR model adaptation to different environments. Before the conclusion, the literature methodology \& industrial synthesis are discussed. Finally, we conclude the paper.

\section{Overview of SCOR Model}

The SCOR model, developed by the Supply-Chain Council, is a process reference model that serves as a 
diagnostic tool for supply chain management. In 1997, the Supply-Chain Council released the first version of the SCOR model. It included Plan, Make, Source, and Deliver as the stages of the supply chain in addition to metrics, best practices, and technology (Phelps, 2006; Galazzo, N. 2006; Magnusson, 2010). Version 4 was the first to include the Return stage of the supply chain. Currently, Version 10.0 of the SCOR-model is the twelfth revision since the Model's introduction in 1996. Revisions of the Model are made when it is determined by Council members that changes should be made to facilitate the use of the Model in practice. The SCOR model (version 10.0) consists of four major components:

- Performance: Standard metrics to describe process performance and define strategic goals.

- Processes: Standard descriptions of management processes and process relationships.

- Best Practices: Management practices that produce significant better process performance.

- People: Standard definitions for skills required to perform supply chain processes.

SCOR model has been warmly greeted by industries since it was introduced (Vijay, 2005). This process reference model designed to facilitate communication among supply chain members (SCC, 2010). It provides a common language for communication and is used to describe a measure and evaluate the supply chain configuration. SCOR combines the concepts of the business process reengineering, benchmarking and best practices. The SCOR model is developed and aimed to the modeling and improvement supply chain of developed countries.

SCOR model encompasses all the activities of suppliers, customers, material flows and all market interactions. The SCOR model consists of five basic processes, Plan (P), Source (S), Make (M), Deliver (D) and Return (R). The SCOR modeling approach starts with the assumption that any supply chain process can be represented as a combination of the processes P, S, M, D and R. The Plan process balances to best meet the demand and supply the sourcing, manufacturing and delivery requirements. SCOR model contains three levels of process details. Level 1 is the top level that deals with process types. It defines a scope of a supply chain. Level 2 is the configuration level which deals with process categories. Level 3 is the process element level and is the lowest level in the scope of SCOR model. Table 1 shows the SCOR model process definition at level 1.

\section{Insert Table 1-here}

The MIDC is attempting to accelerate and improve their performance to better manufacture products and provide services. To achieve this target, industrial organizations are seeking to optimize their processes within the supply chain. Companies in developing countries should improve their performance by implementing performance measurement systems. Thus, Performance measurement systems shall be considered as a critical element in translating supply chain strategy into action. There is a high need of research in respect of adapting the performance measurement in the context of developing counties to suit their environmental and local factors.

\section{Challenges \& Barriers for the SCOR Adaptation in Developing Countries}

Managing the supply chain within a single country is complicated due to various types of uncertainties in demand, supply and process. In the most developed countries, there are limited uncertainties in availability of the basic necessities for any kind of business such as power, information communication \& technology (ICT), roads, water, etc. However, in developing countries infrastructure is weaker and that poses several newer types of challenges that developed countries have not faced. It may even cause successful well tested strategies and models that worked in developed economies to fail.

A classical example is that of Wal-Mart (Han et al., 2002) which has an efficient network of cross docking facilities in the US that store minimal inventory in them while simultaneously enabling more frequent suppliers to the retailer stores. When Wal-Mart went into operation into South America (Brazil) and Korea, it was very difficult to run a logistics system based on such-docking facilities and had to adapt its approach. Wal-Mart has faced big challenges on-time delivery and put products on the shelf for its customers. Timely delivery of merchandise is an ideal concept in the bumper-to-bumper traffic in Sao Paulo like Seoul in Korea, where Wal-Mart depends on suppliers or contract truckers to deliver most of its goods directly to stores. Consequently, Wal-Mart lost around $\$ 58$ to $\$ 78$ loss since starting up operation in 1995 up to 1995 (Simchi-Levi, Kaminsky, \& Simchi-Levi, 1999). In addition, it has faced challenges in creating collaborative partner due to lack of trust between manufacturers and retailers on its operation on Korea. Therefore, operating supply chains in developing nations often require firms to enable to tailor their existing supply chain strategies and models or develop newer ones for that environment (Han L., 2007 \& Han, 2002).

Most developed countries, companies have been implemented the SCOR model successfully with its building 
blocks: business processes, key performance indicators, best practices and relevant technology (Phelps, T., 2006). However, SCOR model is not a magic tool; it is somewhat difficult, resources and time-consuming to implement the SCOR model in manufacturing industries. Manufacturing industries in economically developed countries such as USA and EU are well-designed and supported by an outstanding infrastructure, which, in turn, enables smooth information flow and physical goods among supplier, manufacturer and customers.

Lack of a well-developed infrastructure, which is a pre-condition for successful supply chain operation \& improvement, imposes additional pressure on implementation of SCOR model. This condition creates difficulties to synchronize the demand and supply operation in the companies. This creates failure of smooth supply chain operation, which usually results in inventory build-up along the supply chain (Andel, 1996; Andreoli, 1995; Davis, 1995). Craighead and Shaw (2003) argue that supply chain performance is dependent on multiple capabilities: SC relationship capabilities, manufacturing firm capabilities, ICT capabilities and operational capabilities. These four capabilities, along with final customer's desire, create and accumulate the value of the supply chain. Developed countries manufacturing industry has been in well-established and status in the four capabilities for SCOR model successful implementation. Almost all manufacturing industries in the developing country are in stage of very low and limited SC relationship capabilities, manufacturing firm capabilities, information and communication technology capabilities and operational capabilities.

The MIDC is small and medium enterprises, which produce Food, Beverages, Textile and Leather products. From a technical perspective, supply chain operations have been manipulated on a manual or semi-automated basis with the support of basic or legacy applications. Lack of connectivity, limited resources, and skilled labor are still challenging for direct application of the model. There is often the system of shortage of qualified and experienced professional employees, weak and lack of ICT as well as inexperience in the use of such technologies. Several cultural and organizational challenges face ICT base advanced manufacturing technology implementation (see Figure 2). The overall lack of management skills and expertise often makes it not viable for developing countries to develop complex structures such as sophisticated performance measurement systems (Waal, 2007). One important barrier for developing country producers in the performance measurement system is the lack of know-how and practical experience on such application.

\section{Insert Figure 2-here}

Other considerable obstacles are related to poor supporting infrastructure of the developing countries. This infrastructure leads to unresolved issues that are demonstrated in late delivery and material shortage. Magder (2005) has shown this issue by investigating the Egyptian apparel industry emphasized the need to improve the supporting infrastructure of the country to extend its export rate of industries such as: apparel, fresh food and flowers. This can be considered as the major barrier facing developing countries manufacturing industries to proceed in their upgrade.

The SCOR model has developed for a developed countries environment may not be suitable for DCMI. We need to find a way on finding solution for adaptation to developing countries. For the intended task, we need to adapt the SCOR model to the MIDC environmental factors and conditions. These factors have the different impact on the model that did not expect in developed countries as explained above with SC relationship level, culture, infrastructure, human and ICT capability issues in the consideration for our adaptation.

\section{Adapting SCOR Model to Different Scenarios}

The SCOR model has been through several revisions. Fig. 3 provides a timeline of revisions to the model adapted from Phelps (2006). The latest release of the SCOR model, version 10.0, was in 2010. The SCOR model version 10.0 provides a framework for business processes, metrics, best practices, and people.

In addition to timely revision of the SCC, different academicians and practitioners have been trying to adapt the SCOR to their local operating conditions and environmental factors. In our literature review, we have encountered a number of research works and papers on SCOR model adaptation. We have summarized the papers into five categories for discussion as stated as follows:

- to manufacturing industry environment

- to the service industry environment

- to the military environment

- to the geographical information system (GIS) and information technology (IT) environment

- to the logistics operation's environment

- to the collaborative supply network environment 


\section{Insert Figure 3-here}

\subsection{SCOR model adaptation to manufacturing industry environment}

Even though, the SCOR model designed and applied for manufacturing industries, based on identified limits and weaknesses, researches and results from different practitioners and academicians, then the SCOR model can be extended further increasing its proven practical relevance. There are a few research papers on adaptation of SCOR model to the manufacturing industry environment.

The ongoing research done by Fronia et al. (2009) has shown how SCOR may be extended in order to develop a framework for supply chain design. The researcher has suggested six standard process models for source process in level 2. In comparison to those natives to SCOR, these six models are shown to be advantageous, distinguishing more clearly between different modes of procurement (see Figure 4). Successively, it is demonstrated how this level two models were detailed on the SCOR level 3 and 4. Using the above-mentioned models and framework appropriate data can be gathered for the process cost, and cost of capital ties up in the structured and easily manner. This step also develops as a basis for the next step in the supply chain design. The additional analysis of logistic performance indicators, that are critically contingent on the supply chain configuration, facilitates the evaluation of the whole supply chain performance as well as the impact of strategic logistic measures.

\section{Insert Figure 4-here}

Companies have to satisfy a multitude of needs to thrive. Ensuing conflicts between targets have to be resolved in order to maximize the companies' market value, the decision field being of high complexity. Some methods existing to today offer useful input to resolve this decision problem or at least parts thereof. Nevertheless, several consulting projects for German companies completed by Wriggers et al. (2009) ascertained demand for an easy to use the decision support system which targets this optimization problem. This paper describes a support system for sourcing, which was successfully applied to resolve this problem, using an adaptation of SCOR as a basis.

Hwang et al. (2008) identified critical metrics for the sourcing processes in the thin-film transistor-liquid crystal display (TFT-LCD) industry supply chain in Taiwan is established by using the SCOR V.7.Model. Although the study focuses on the Source management process, the other four management processes are also considered. No extensions are made to the model.

Based on the SCOR model, Ren at al. (2006) presented a comprehensive framework for SC performance management, which includes all aspects of performance management from performance measurement to performance improvement. The methods for performance model design and performance analysis are mainly discussed. The framework can be used for supply chain diagnosis, supply chain transformation, and the exploration for supply chain operational mechanisms. Especially, it can also be used as the guide for business application design, e.g. the business performance management system (BPMS).

Desodt et al. (2007) collected information from textile and garment industry supply chains in order to model the supply chain. Then, using these performance data, they identified important variables and investigated the endogenous and exogenous relationships among variables. The SCOR model had to be adapted to the study.

The study done by Han et al. (2007) integrates the concepts of the supply chain, a collaborative product commerce, and SCOR to propose the collaborative supply chain operations reference model (CSCOR) in the product life cycle. This model consists of four hierarchical levels: collaborative business model; collaborative cooperative model; collaborative process model; and, a collaborative operational model. Based on project management (PM), the CSCOR has five core procedure plan, source, make, delivery and return. This study also assesses the effectiveness of the CSCOR by applying it to the regional manufacturing industry in China. The contribution of this study is that it extends the SCOR model in proposing the CSCOR and establishes a universally applicable collaborative supply chain reference model. This study also applies the CSCOR and implements a system to the electronics industry, which serves as an example of best practices for a collaborative supply chain involving customers, manufacturer, contract firms and suppliers.

Vanany et al. (2005) adapted SCOR model as a basis to develop a complete Supply Chain Performance Management System (SCPMS) for a company in the lamp production industry. No adjustments or extensions are made to the existing five management processes in SCOR. However, SCOR metrics as well as another additional metrics is used to develop the integrated SCPMS.

Prabir (2007) investigated through different performance measurement systems. SCOR model was selected for final adaptation for Indian Apparel and Textile Supply Chain Networks. Supply chain performance measurement 
framework is developed in terms of efficiency with respect to key functional parameters spanning four different operation domains namely source, plan, make and deliver. There are five primary key performance indicators (KPI) identified in each operation domain.

Lim et al. (2007) explore the importance of the performance measurement system for adaptive supply chain for fulfilling the demand of current dynamic and ever-changing market needs; review the development in the area of SC performance measurement. They have found out that although there are quite a number of publications, which stressed the importance of the measurement and proposed approaches and methods, there is still a lack of a holistic system that can link strategy and performance measurement. After identifying the most important characteristics attributes \& activities of a supply chain has and the performance metrics that contributes the attributes, they have proposed a performance measurement framework which is used to evaluate the performance of an adaptive supply chain and helps the companies to identify, evaluate and monitor the key areas which can help them to maintain their pace and speed of their success.

\subsection{SCOR model adaptation to service industry environment}

The SCOR models have many limitations when applied to the services industry. Two of the most significant limitations of the SCOR model are the semantics and process types. The limiting factor of the semantics and process types is the connotation of the embedded definitions. An example is the definition and use of the "MAKE" process. Semantically the "MAKE" definition in SCOR is the process of manufacturing that adds value to a product (SCC, 2010). James H.B., (2206) has shown his SCOR model adaptation results for service sector. The conversion of the SCOR "MAKE" process to service semantics creates a situation that is lost in translation. In fact, "MAKE" in the service industries does not have a direct translation. Another process that is not in any services setting is the "RETURN" process. One reason is that the physical return of a service is highly improbable. This is because once a service is rendered the service is consumed, thus invalidating the semantic and process descriptions in relation to services (James, 2006).

Ellram et al. (2004) evaluated the applicability of a Service SC based on three product-based manufacturing models: Global Supply Chain Forum (GSCF) Framework, the SCOR model and Hewlett Packard's supply chain management model. Lambert et al. (2005) compared the SCOR model with the GSCF framework in four criteria - scope, intra-company connectedness, inter-company connectedness and drivers of value generation - and identified their relative strengths and weaknesses. Ellram et al. (2004) translated this latter model to service SC and identified key functions as capacity and skills management, demand management, customer relationship management, supplier relationship management, service delivery management and cash flow management (see Figure 5).

\section{Insert Figure 5-here}

Laura (2006) has analyzed SCOR limitations for application in Telecom industry. Enhancement to SCOR and a SCOR based practical roadmap for SCM modeling and implementation are proposed and applied in a case study for Telecom industry. The paper also analyses qualitative and quantitative benefits from the SCOR implementation in Telecom industry.

Based on intensive literature research and results of a European survey covering a wide range of industrial branches, the assumption was validated that there exists no standard system so far. On the other hand, there is an unsatisfied business need to quantify both the efficiency and effectiveness of service operations and make their impact on customers' overall performance transparent. Focusing on this area, Lange et al. (2007) presented the conceptual new standard performance framework for the measurement of operational performance indicators in the domain of industrial service.

Baltacioglu et al. (2007) developed a new framework, which is built on the existing knowledge derived from the SCOR and Ellram et al. models, with an application in the healthcare industry. The name of the model (IUE-SSCM) is derived from the initials of the affiliated organization of the authors (Izmir University of Economics (IUE)) and Service Supply Chain Model (SSCM). After thorough investigation, they constructed IUE-SSCM model to cover three basic units in the chain: the supplier, the service provider and the customer (see Figure 6). The service provider is the focal company in the supply chain that performs the service, and it claims the manufacturer's role in the traditional supply chain literature. The supplier is the company which supplies additional services to the service provider and/or directly to the service provider's customer where these services contribute directly to the production of the core service in the chain.

\section{Insert Figure 6-here}

One opportunity to support service providers in gaining transparency about their profitability and performance 
lies in the standardization of the service processes. This allows for the implementation of tools and methods to measure and control performances and costs of service contracts more efficiently and effectively. The EU-funded project InCoCo-'S' (Innovation, Coordination and Collaboration in Service Driven Manufacturing Supply Chains, EC STRP 017192) strives for the development of reference processes for industrial services. Based on the SCOR model (Supply-Chain Operations Reference model) offered by the Supply-Chain Council, the project developed a reference framework for an efficient and effective integration of five different types of industrial services into manufacturing supply chains. This reference framework, called the InCoCo-'S' Reference Model (IRM), consists of generic planning, execution, and support processes with input/output relationships, assigned best practices and a comprehensive set of performance indicators. The five different service clusters considered in the project are logistics, retrofit, maintenance, packaging and quality control. These services cover the phases of Source, Make and Deliver of the SCOR model (Gerosa et al., 2001; Schneider et al., 2007; Lang et al., 2007).

\subsection{SCOR model adaptation to military environment}

Like any other sectors, the military industry has always used the knowledge from other sectors for improvement of its activities. The South African National Defense Force (SANDF) contracted the CSIR to investigate and propose methods to improve its logistics and inventory accounting capabilities. According to Bean et al (2009) SANDF contracted a company to investigate and propose methods to improve its logistics and inventory accounting capabilities. The researcher was decided that supply chain management in conjunction with the SCOR model can be used to improve the SANDF's logistics effectiveness and the accounting of its inventory. Therefore, the SCOR V 9.0 Model was chosen as a basis for the SANDF's supply chain. Three case studies with increasing complexity were conducted and during these case studies, it was ascertained that the SCOR model did not cover the activities, with regard to materiel, in the SANDF supply chain sufficiently. Consequently, the SCOR model had to be extended to be more suitable for the military environment.

The results of extension analysis include the introduction of a sixth management process, USE, which describes the use of ammunition and user systems, such as an armor regiment, during training and operational exercises. The MAKE Process is extended to include maintenance as well as the modification of material. A fourth process category is included in SOURCE to deal with captured materiel from the enemy that can be used by SANDF against the enemy in the future. It was necessary to add two RETURN process categories. This was namely Maintenance Return for Disposal, were unusable material is destroyed by the SANDF and Maintenance Return for the Proofing of Ammunition where ammunition is proofed by the SANDF (Figure 7).

\section{Insert Figure 7-here}

Earlier to the above research, United States of America, Deputy under Secretary of Defense (2000) has used the SCOR model to provide a structured approach to implement SC processes in Department of Defense (DoD) logistics organizations. A Maintain management process is used instead of Make, due to the need for materiel repair in the DoD supply chain. The Return Management Process is excluded from the study.

\subsection{SCOR model GIS and IT environment}

According to Dangermond (1999) and Tomlinson (2000), one of the challenges for geographical information system (GIS) units in the 21 st century is to be able to manage themselves successfully in order to deliver the right product at the right time to the right customer. It also indicated that by Tomlinson (2000), there will be several management tools available to assist GIS units to enable them to manage themselves (Schmitz, 2009).

Schmitz (2009) used the SCOR model to introduce supply chain management into a GIS unit in order to improve the effectiveness and efficiency of the unit when creating a GIS product. This SCOR focuses on the management of the data used by a GIS unit. In the extended version of the SCOR model, GISDataSCOR, the original five management processes are used, and the Make Process is extended to include an extra process category for maintenance (M4: Maintain-to-Stock).

One of the more recent works exploring the intricacies of SCOR is the research performed by Fayez. This work documented the weaknesses of the SCOR model and developed views of the framework to enhance the capability of the model (Fayez, 2005). Enhancements to the SCOR model include the ability to define interactions using a common ontology at the enterprise and functional unit level as well as clarifying the complexities involved within the supply chain. One of the conclusions drawn from this research is the need for a variety of views for other sectors outside of manufacturing.

Dong et al. (2006) used the SCOR model as a basis for developing a complete methodology and framework for SCM problem solving. The SCOR model is not adjusted, but simulation and optimization techniques are used 
with the SCOR model to develop SmartSCOR, which is an integrated platform that supports end-to-end supply chain transformation using various techniques.

\subsection{SCOR model adaptation to logistics operations environment}

The research done by Lai et al. (2002) has been conducted with aims to investigate the construct of, and develop a measurement instrument for, supply chain performance (SCP) in transport logistics. Based on the SCOR model and various established measures, a measurement model and a measurement instrument for supply chain performance in transport logistics are developed. A SCP 26-item measurement instrument constructed. This can be used to evaluate service effectiveness for shippers, operation efficiency for transport logistics service providers, and service effectiveness for consignees. The empirical findings suggest that the measurement instrument is reliable and valid for evaluating SCP in transport logistics.

Increasing dynamics are making efficient management of the supply chain difficult. The bullwhip effect is known to be a major source of this inefficiency so there is a considerable amount of literature analyzing its causes. However, the reported outcomes are not comparable because they consider business environments and make different assumptions regarding operative processes. Kim et al. (2007) proposed a SCOR based framework for modeling and analyzing the bullwhip effect so that practitioners can evaluate the performance of their supply chain, and establish a strategy to improve its performance.

\subsection{SCOR model adaptation to collaborative environment}

There are some researches to also the SCOR model adaptation to collaborative networks. Some researchers are adapted to this application of the SCOR model and others, specifically about a virtual organization, such as the virtual organization performance measurement system by Seifert et al. (2008). At the same time, there are some conceptual models such as a SCOR based model (Westphal et al., 2008). The adapted and conceptual models consist of gathering some concepts in order to build a framework that can support decision makers so that they can achieve the specifics purposes or strategies and identify new challenges (Francisco et al., 2009).

Hieber (2001), developed integrated model of collaborative performance measurement will make a contribution to support improvements in trans-corporate logistics $\mathrm{s}$ well as to give guidelines for implementation of supply chain management. The SCOR model served as a basis to the proposed performance measurement model. However, to overcome its identified shortcomings for the new trans-corporate environment, the two phase integral model consisting of generic high level and aggregate corporate performance indicators as well as including the specific implementation guidelines has been developed.

\section{Research Methodology and Industrial Scenario Analysis}

\subsection{Research methods}

We can get generic information about the research methods for SCOR model adaptation even though the literatures are limited. Table 2 shows a summary of the research methods used in the different literature. From the number published data reviewed, there is a dominance of case study and conceptual approaches with fewer undertaking with large-scale questionnaire surveys. We can observe the application of grounded theory approach (GTA) in the supply chain areas has increased in recent years.

Insert Table 2-here

\subsection{Industrial scenario analysis}

Table 3 illustrates the different industrial scenarios that have been studied in the SCOR model adaptation literature. Overall, manufacturing industry is the dominant sector for the SCOR model adaptation literature, followed by the service industry.

From this review on SCOR model adaptation in this section, it can be concluded that:

- There are possibilities of adaptation of SCOR model to different scenarios that suit the environment it operates.

- Different business processes and working practices of the supply chain can be mapped and compared with the original SCOR model to help determine their applicability and adaptability. This approach would suggest that how adaptation can be more suited to the different supply chain's environment.

- Most analysis started from the analysis of the business process. Then, the selection and determination of appropriate performance measures have been followed.

Insert Table 3-here 


\section{Conclusion \& Future Direction}

From our literature review, we can observe the possibility of SCOR model adaptation to different environment and context even far from SCOR model scope area. There is no question that in adapting SCOR model, which has proven to be effective. Developing countries has a better alternative for their organization local environment and operating condition than investing limited and scarce resources in efforts, which do not amount to much more than 'reinventing the wheel'. The state-of-the-art techniques and practices currently in operation in developed countries organizations can undoubtedly be of great benefit to organizations in developing countries.

The SCOR model has emerged as a quasi-standard business reference model across a range of industries. Global manufacturing and distribution activities are demanded more integration of the supply chain in the recent years, including developing countries. To make more effective and efficient supply chain operation and integration, developing countries must be involved as part and parcel of the business activities. For this effect, developing countries should find new or adapt the existing techniques for their supply chain modeling and improvement. This paper has presented a literature review for the adapting SCOR model literature.

An analysis of the research methods across literature confirms that research is predominantly case or conceptual based research. More testing is required in the future research of the SCOR model adaptation. This review highlights future directions for research focused around three themes: developing a business process, developing tailored performance metrics and the identifications of appropriate applications of best practices for the MIDC.

\section{References}

Abdel Aziz, A. E., Dixon, R., \& Ragheb, M. A. (2005). The contemporary performance measurement techniques in Egypt: a contingency approach. Paper presented during the EDHEC conference.

Abdelsalam, H. M., \& Fahmy, G. A. (2009). Major variables affecting the performance of the textile and clothing supply chain operations in Egypt. International Journal of Logistics Research and Applications, 12(3), 147-163. http://dx.doi.org/10.1080/13675560902729334

Baltacioglu Tuncdan., Ada Erhan., Kaplan, Melike D., Yurt, Oznur., \& Kaplan, Y. Cem. (2007). A New Framework for Service Supply Chains. The Service Industries Journal, 27(2), 105-124. http://dx.doi.org/10.1080/02642060601122629

Bean, W. L., Schmitz, P. M. U., \& Engelbrecht, G. N. (2009). Adapting the SCOR Model to suit the military: A South African Example. In Proceedings of the 14th Annual Logistics Research Network Conference: Volatile and Fragile Supply Chains.

Bititci, U. S., \& Turner, T. (2000). Dynamics of performance measurement systems. International Journal of Operations \& Production Management, 20(6), 692-704. http://dx.doi.org/10.1108/01443570010321676

Castelli, C. (2006). Supply chain management strategies in the luxury industry. [Online] Available: http://www.ingegneriagestionale.uniroma1.it/aiig2006/atti\%20convegno/pdf/doctoral\%20supply/Castelli.pdf

Christopher, M., \& Towill, D. (2001). An integrated model for the design of agile supply chains. Int. J. Phys. Distrib. \& Logist. Management, 31(4), 235-246. http://dx.doi.org/10.1108/09600030110394914

Cocca, P., \& Alberti, M. (2010). A framework to assess performance measurement systems in SMEs. Int. Journal of Productivity and Performance Management, 59(2), 186-200. http://dx.doi.org/10.1108/17410401011014258

Deloitte Consulting. (1999). Energizing the supply chain: Trends and issues in supply chain management. [Online] Available: http://www.deloitte.com/dtt/research

Deputy under Secretary of Defence. (2000). DoD Supply Chain Management Implementation Guide. Office of Supply Chain Integration (Logistics Management Institute).

Dong, J., Ding, H., Ren, C., \& Wang, W. (2006). IBM Smart SCOR - A SCOR Based Supply Chain Transformation Platform through Simulation and Optimization Techniques. Research Report (IBM Research Division, China).

Ellram, L. M., Tate, W. L., \& Billinton, C. (2004). Understanding and Managing the Services Supply Chain. The Journal of Supply Chain Management, 40(4), 17-32. http://dx.doi.org/10.1111/j.1745-493X.2004.tb00176.x

Fayez, M. (2005). An automated methodology for a comprehensive definition of the supply chains using generic ontological components. Dissertation, University of Central Florida.

Francisco, D. R., \& Azevedo, A. (2009). An SSM-Based Approach to Implement a Dynamic Performance 
Management System. In L.M. Camarinha-Matos et al. (Eds.), IFIP International Federation for Information Processing, 307, 476-483. http://dx.doi.org/10.1007/978-3-642-04568-4_49

Fronia, P., Wriggers, F. S., \& Nyhuis, P. (2008). A Framework for Supply Chain Design. EngOpt 2008-International Conference on Engineering Optimization.

Galazzo, N. (2006). Using SCOR model in a real Collaborative Sourcing scenario. VIB-ABCAL_PICS, Supply $\begin{array}{llll}\text { Chain } 2006 . & \text { Award } & \text { Available: }\end{array}$ http://archive.supply-chain.org/galleries/taxonomy/NGalazzo\%20Using\%20SCOR\%20model\%20in\%20a\%20re al\%20Collaborative\%20Sourcing\%20Scenario.pdf

Gerosa M., \& Taisch M. (2008). A novel Industrial Services Reference Model. 14th International Conference on Concurrent Enterprising.

Han L. Lee., \& Chung-Yee Lee. (2007). Building supply chain excellence in emerging economies. International Series in Operations Research \& Management Science, 98. http://dx.doi.org/10.1007/978-0-387-38429-0

Han, D., Kwon, I. G., Bae, M., \& Sung, H. (2002). Supply chain integration in developing countries for foreign retailers in Korea: Wal-mart experience. Computer \& Industrial Engineering, 43, 111-121. http://dx.doi.org/10.1016/S0360-8352(02)00070-0

Hieber, Ralf Franz. (2001). Supporting transcorporate logistics by collaborative performance measurement in industrial logistics networks. PhD Thesis, Swiss Federal Institute of Technology, Zurich.

Holmes J., Gutierrez de Pineres S., \& Kiel L. D. (2006). Reforming Government Agencies Internationally: Is There a Role for the Balanced Scorecard?. International Journal of Public Administration, 29, 1125-1145. http://dx.doi.org/10.1080/01900690600854803

Huang, S. H., S. K. Sheoran., \& H. Keskar. (2005). Computer-assisted supply chain configuration based on supply chain operations reference (SCOR) model. Computers \& Industrial Engineering, 48(2). http://dx.doi.org/10.1016/j.cie.2005.01.001

Hwang, Y. D., Lin, Y. C., \& Jung, L. Jr. (2008). The performance evaluation of SCOR sourcing process: The case study of Taiwan's TFT-LCD industry. International Journal of Production Economics, 115(2), 411-423. http://dx.doi.org/10.1016/j.jpe.2007.09.014

Irfan D., Xiaofei X., \& Shengchun D. (2008). A SCOR Reference Model of the Supply Chain Management System in an Enterprise. International Arab Journal of Information Technology, 5(3), 288-295.

James H. Barnard. (2006). A Multi-View Framework for Defining the Service Supply Chain using Object Oriented Methodology. PhD thesis, Department of Industrial Engineering and Management Systems in the College of Engineering and Computer Science at the University of Central Florida Orlando, Florida.

Kasi, Vijay. (2005). Systemic Assessment of SCOR for Modeling Supply Chains. In Proceeding of the 38th Hawaii International Conference on System Sciences, 03/06, 87b. http://dx.doi.org/10.1109/HICSS.2005.574

Kassahun Tilaye. (2010). Rethinking institutional excellence in Ethiopia: adapting and adopting the balanced scorecard (BSC) model. Journal of Business and Administrative Studies, 2(1), 22-53.

Khalifa, N., White, A., \& EISayed, A. (2008). Supply Chain Challenges in Developing Countries: Cross Industry Case Studies. Cybernetic Intelligent Systems, 2008, 7th IEEE International Conference, http://dx.doi.org/10.1109/UKRICIS.2008.4798929

Kim, H., Park, J., Chang, T. W., Jeong, H., Kim, K. T., \& Park, J. (2007). A Model and Analysis of the Bullwhip Effect Using a SCOR-Based Framework. Asia Simulation Conference, 5(1), 12-20. http://dx.doi.org/10.1007/978-3-540-77600-0_2

Lai, K., E. W. T. Ngai., \& T. C. E. Cheng. (2002). Measures for evaluating supply chain performance in transport logistics. Transportation Research Part E: Logistics and Transportation Review, 38(6), 439-456. http://dx.doi.org/10.1016/S1366-5545(02)00019-4

Lange, I., Schnetzler, M., Schneider, O., Osadsky, P. (2007). Design of a Performance Measurement System for Industrial Service Operations. The 2nd International Conference on Changeable, Agile, Reconfigurable and Virtual Production.

Laura, X. X. X. (2006). Supply Chain Modeling and Improvement in Telecom Industry: A Case Study. 2006 IEEE Conference on Industrial Informatics, 8, 1159-1164. http://dx.doi.org/10.1109/INDIN.2006.275782

Lim R. Y. G., Laura X., Bib M. A., \& Watcharavee C. (2007). Development of a Performance Measurement 
Framework for Adaptive Supply Chain. Paper presented at the 2nd International Conference on Operations and Supply Chain Management.

Lin, L. C., \& Li, T. S. (2010). An integrated framework for supply chain performance measurement using six-sigma metrics. Software Quality Journal, 18(3), 387-406. http://dx.doi.org/10.1007/s11219-010-9099-2

Magder, D. (2005). Egypt after the Multi-Fiber Arrangement: Global Apparel and Textile Supply Chains as a Route for Industrial Upgrading. Working Paper Series: Institute for International Economics.

Magnusson, L. (2010). Performance management using SCOR. Ericsson AB, Supply Chain Council.

Marco Gerosa., \& Marco Taisch. (2008). A novel Industrial Services Reference Model. 14th International Conference on Concurrent Enterprising.

Nyhuis P., \& C. Wolter. (2002). Quantifying the Rationalization Potential in Logistics through Supply Chain Design. International Workshop on Performance Measurement IFIP WG 5.7, Hannover.

Olugu, E. U., \& Wong, K. Y. (2009). Supply Chain Performance Evaluation: Trends and Challenges. American J. of Engineering and Applied Sciences, 2(1), 202-211: http://dx.doi.org/10.3844/ajeas.2009.202.211

Phelps, T. (2006). SCOR and benefits of using process reference models. In proceedings of the 2006 Supply Chain International Conference, Taipei, Taiwan.

Prabir, J. (2007). An Investigation into Indian Apparel and Textile Supply Chain Networks. Unpublished Ph D Dissertation (Nottingham Trent University, UK).

Ren, C., Dong, J., Ding, H., \& Wang W. (2006). A SCOR-Based Framework for Supply Chain Performance Management. Service Operations and Logistics, and Informatics (IEEE International Conference), 21-23, $1130-1135$.

Ren, Tong. (2008). Application of Supply Chain Performance Measurement Based on SCOR Model. Present at the 4th International Conference Wireless Communications, Networking and Mobile Computing, 1-4. http://dx.doi.org/10.1109/WiCom.2008.1490

Russel, D. M., Ruamsook, K., \& Thomchick, E. A. (2009). Ethanol and the Petroleum Supply Chain of the Future: Five Strategic Priorities of Integration. Transportation Journal, 48(1), 5-22.

Samuel, H. H., Sunl, K. S., \& Wang, G. (2004). A review and analysis of supply chain operations reference (SCOR) model. Supply Chain Management: An International Journal, 9(1), 23-29. http://dx.doi.org/10.1108/13598540410517557

Schmitz, P. M. U. (2007). The use of supply chains and supply chain management to improve the efficiency and effectiveness of GIS units. PhD thesis, University of Johannesburg, South Africa.

Schmitz, PMU et al. (2007). Understanding data supply chains by using the Supply-Chain Operations Reference (SCOR) model. Logistics Research Network Annual Conference.

Schneider, O., Lange, I., \& Nitu, B. (2007). Enabling Industrial Service Providers to offer Comprehensive Service Contracts. In Proceedings of the 13th International Conference on Concurrent Enterprising (pp. 4-6). Sophia-Antipolis.

Seifert, M., Wiesner, S., \& Thoben, K. D. (2008). Prospective Performance Measurement in Virtual Organisations. In Camarinha-Matos, L. M., \& Afsarmanesh, H. (Eds.), Collaborative Networks: Reference modeling. Springer, New York. http://dx.doi.org/10.1007/978-0-387-79426-6_22

Shepherd, C., \& Gunter, H. (2006). Measuring supply chain performance: Current research and future directions. International Journal of Productivity and Performance Management, 55(3), 242-258. http://dx.doi.org/10.1108/17410400610653219

Shewchuk P. J. (1998). Agile manufacturing: one size does not fit all. In Proceeding of the IFIP.

Waal, A. A. de. (2007). Is performance management applicable in developing countries? The case of a Tanzanian college. International Journal of Emerging Markets, 2(1), 69-83. http://dx.doi.org/10.1108/17468800710718903

Westphal, I., Thoben, K. D., \& Seifert, M. (2007). Measuring Collaboration Performance in Virtual Organisations. Establishing the Foundation of Collaborative Networks, 243, 33-42. http://dx.doi.org/10.1007/978-0-387-73798-0_4

Wriggers, F. S., Fronia, P., \& Nyhuis, P. (2008). Capital Allocation in Companies. EngOpt 2008-International 


\section{Conference on Engineering Optimization, 7, 1-5.}

Xia, L. X. X. (2006). Supply chain modeling and Improvement in telecom Industry: A case study. IEEE, 8, 1159-1164. http://dx.doi.org/10.1109/INDIN.2006.275782

Table 1. SCOR Level 1 Process Definitions (SCC, 2010)

\begin{tabular}{|c|l|}
\hline SCOR Process & Definitions \\
\hline Plan & $\begin{array}{l}\text { Processes include gathering customer requirements, collecting information on } \\
\text { available resources, and balancing requirements and resources to determine } \\
\text { planned capabilities and resource gaps. }\end{array}$ \\
\hline Source & $\begin{array}{l}\text { Processes describe the ordering (or scheduling) and receipt of goods and } \\
\text { services. }\end{array}$ \\
\hline Make & $\begin{array}{l}\text { Processes describe the activities associated with the conversion of materials or } \\
\text { creation of the content for services. }\end{array}$ \\
\hline Deliver & $\begin{array}{l}\text { Processes describe the activities associated with the creation, maintenance, and } \\
\text { fulfillment of customer orders. }\end{array}$ \\
\hline Return & $\begin{array}{l}\text { Processes describe the activities associated with the reverse flow of goods back } \\
\text { from the customer. }\end{array}$ \\
\hline
\end{tabular}

Table 2. Research methods from SCOR model adaptation

\begin{tabular}{|l|l|c|}
\hline Methods & SCOR model adaptation research & Number of article \\
\hline $\begin{array}{l}\text { Case studies } \\
\text { (Primary \& } \\
\text { secondary) }\end{array}$ & $\begin{array}{l}\text { Schmitz, 2010; Bean et al., 2009; Irfan et al., 2008; } \\
\text { Han et al, 2007; Sudaryanto et al. 2007; Laura Xu } \\
\text { Xiao Xia, 2006; Vanany et al., 2005; Prabir et al., } \\
\text { 2007; Di Martinelly et al, 2009, James H. Barnard, } \\
\text { 2006, Fronia et al., 2008; Schmitz, 2007, 2008; } \\
\text { Fayez, 2005 }\end{array}$ & 14 \\
\hline Conceptual & $\begin{array}{l}\text { James H. Barnard, 2006; Tuncdan Baltacioglu et al. } \\
\text { 2007; Ellram et al., 2004; Amlan Bora et al. 2004; } \\
\text { Drzymalski et al., 2006; Lim et al., 2007 }\end{array}$ & \\
\hline $\begin{array}{l}\text { Grounded theory } \\
\text { approach (GTA) }\end{array}$ & $\begin{array}{l}\text { Russel et al., 2009; Gerosa et al. 2008; Schneider, } \\
\text { O., Lange, I., Nitu, B. 2007 }\end{array}$ & \multirow{2}{*}{3} \\
\hline Tool/model & $\begin{array}{l}\text { Morciniec et al, (2006); Dong et al., (2006); Fayez, } \\
\text { 2005 }\end{array}$ & 3 \\
\hline $\begin{array}{l}\text { Survey/ } \\
\text { Questionnaires/ } \\
\text { Empirical analysis }\end{array}$ & Hwang et al., (2008); Desodt et al, 2006 & 2 \\
\hline
\end{tabular}


Table 3. Research methods from SCOR model adaptation

\begin{tabular}{|l|l|c|}
\hline Sector & Authors & Number of article \\
\hline $\begin{array}{l}\text { Manufacturing } \\
\begin{array}{l}\text { Industry (General, } \\
\text { Adaptive, }\end{array}\end{array}$ & $\begin{array}{l}\text { Russel et al., 2009; Wriggers et al 2009 Fronia et al. } \\
\text { 2008; Felix et al., 2008; Hwang et al. 2008; Irfa et al., } \\
\text { 2008; Prabil et al., 2007; Desodt et al. 2007; Han et } \\
\text { collabonized, } \\
\text { al., 2007; Vanany et al., 2005; Bora, 2004; Drzmalski } \\
\text { et al., 2006;Lim et al., 2007 }\end{array}$ & 13 \\
\hline $\begin{array}{l}\text { Service Industry } \\
\text { General, hospital, } \\
\text { industrial) }\end{array}$ & $\begin{array}{l}\text { DI Martinelly et al., 2009; Baltacioglu, 2007; James, } \\
\text { 2006; Ellram et al. 2004; Laura 2006; Gerosa et al., } \\
\text { 2008; Schneider et al., 2007, }\end{array}$ & 7 \\
\hline IT \& GIS & $\begin{array}{l}\text { Schmitz, 2007, 2009; Morciniec et al., 2006; Dong et } \\
\text { al., 2006; Fayez, 2005 }\end{array}$ & 5 \\
\hline Military & $\begin{array}{l}\text { Schmitz, 2010; Bean et al., 2009; Deputy Under } \\
\text { Secretary of Defense, 2000 }\end{array}$ & 3 \\
\hline
\end{tabular}

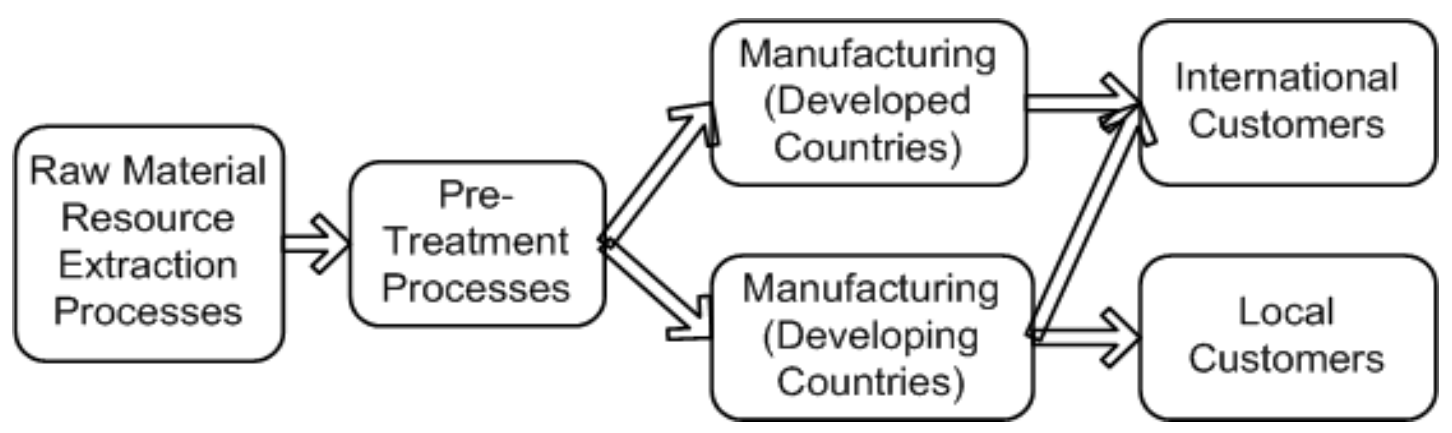

Figure 1. Typical manufacturing supply chain

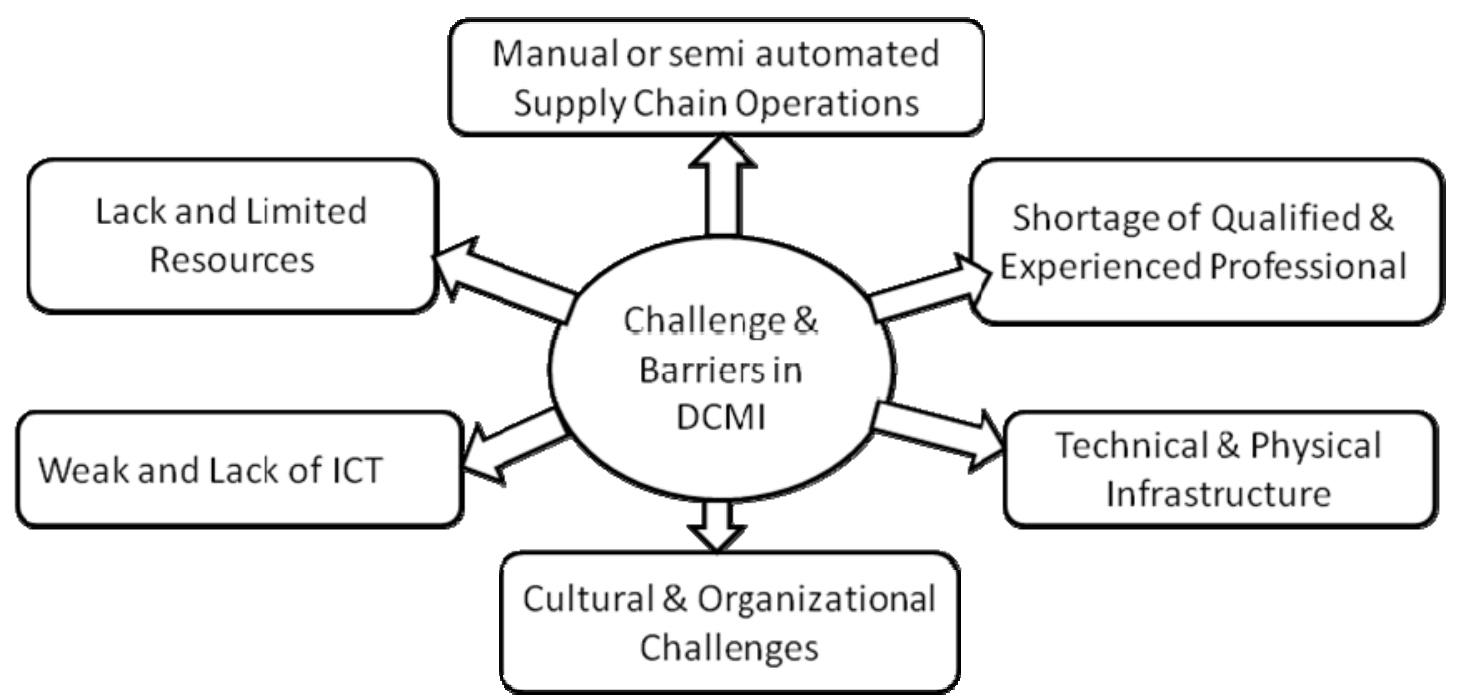

Figure 2. Challenges \& Barriers in MIDC 
Version 3.1

Restructuring of Infrastructure/enable elements.

Restrueturing of metries begun-definitions of

performance attributes developed. Language to

support services as well as tangible goods

prowidud

Vèrsion 3,0

Model Development processes

Model modifies to enhance

infrastructure elements. Speeific

reference to software products

Restructured in 2002 to project Team format

removed. Inputs and outputs enharced

Version 5.0

$1 \quad 1 \quad$ Returns processes introduced

$\begin{array}{ll}\text { Version } 2.0 & \text { E-business practiced upd } \\ \text { Medel medified te resencile } & \text { Metrics re-structuring }\end{array}$

distinctions between discrete and

process industries continued

$$
\text { II I }
$$

Version 4.0

Version 1.0

First version of the Model, Plan, Source, Make, Deliver, metrics, best practice, and technology

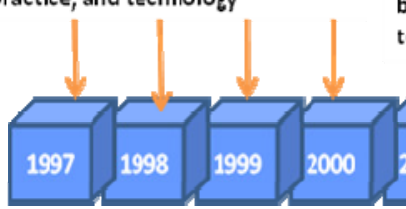

First version of the

Model, Plan, Source,

Make, Deliver,

metrics,

best practice, and

Version 6.0

Version 6.1

Version 7.0

\section{Version 9.0}

Versionto.

In addition bo

process, metrics

and bogt praetieo

people are added

technology

The model includes new metrics, processes and best practices and a completely redesigned reference model

Retail D4, revamped

MRO, Mạke é-biz beșt prạctiçe

Figure 3. SCOR release timeline (adapted from Phelps et al, 2006)

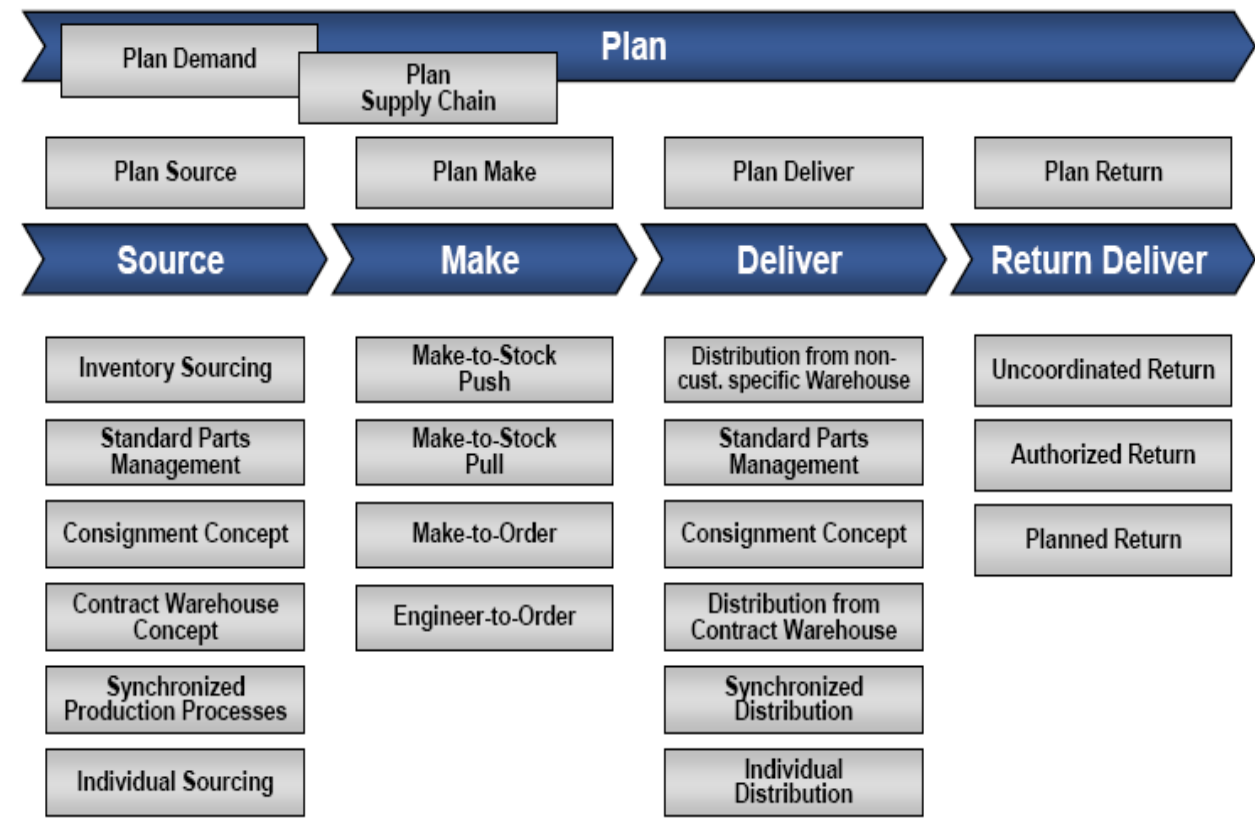

Figure 4. Standard process models - an enhancement of the SCOR model (according to Nyhuiset al.) 


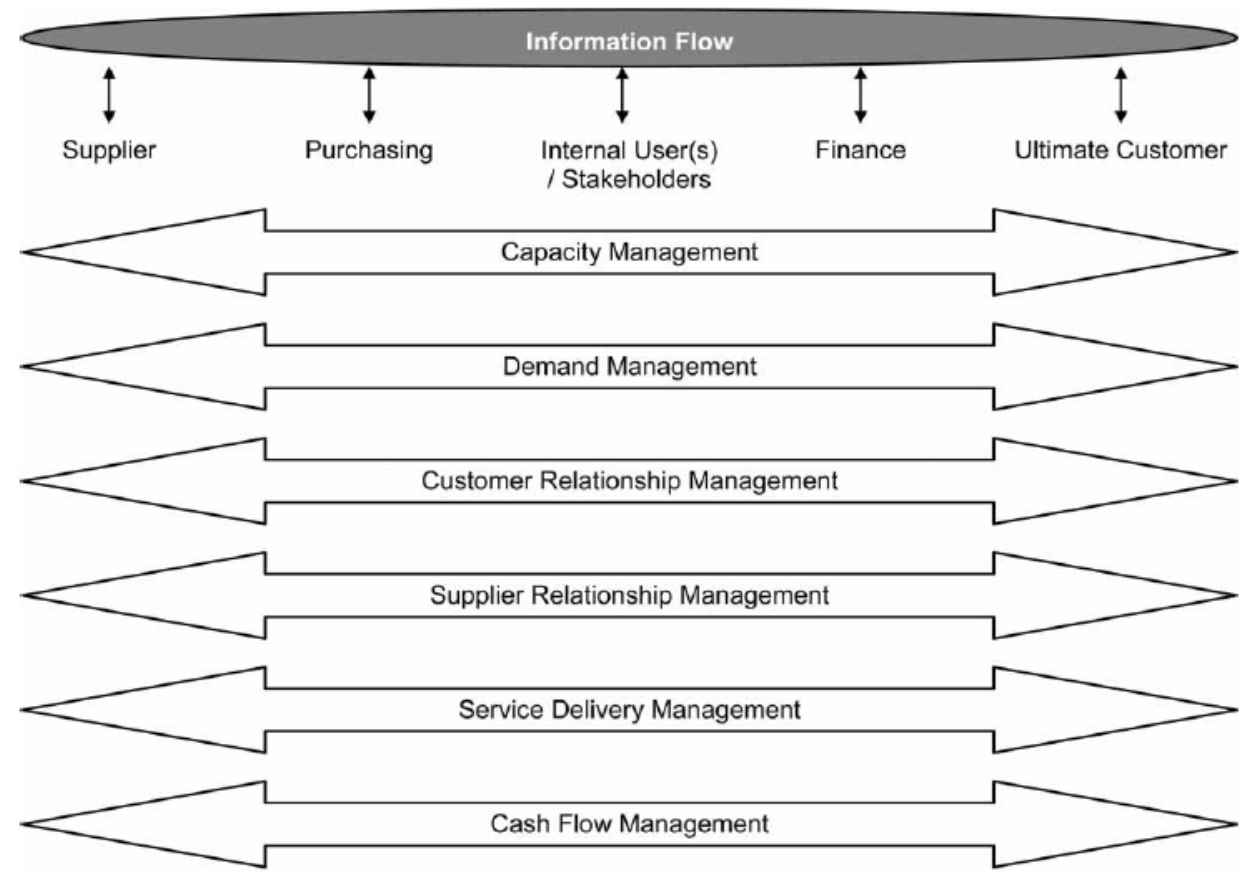

Figure 5. Service supply Chain Model (Ellram et al. 2004)

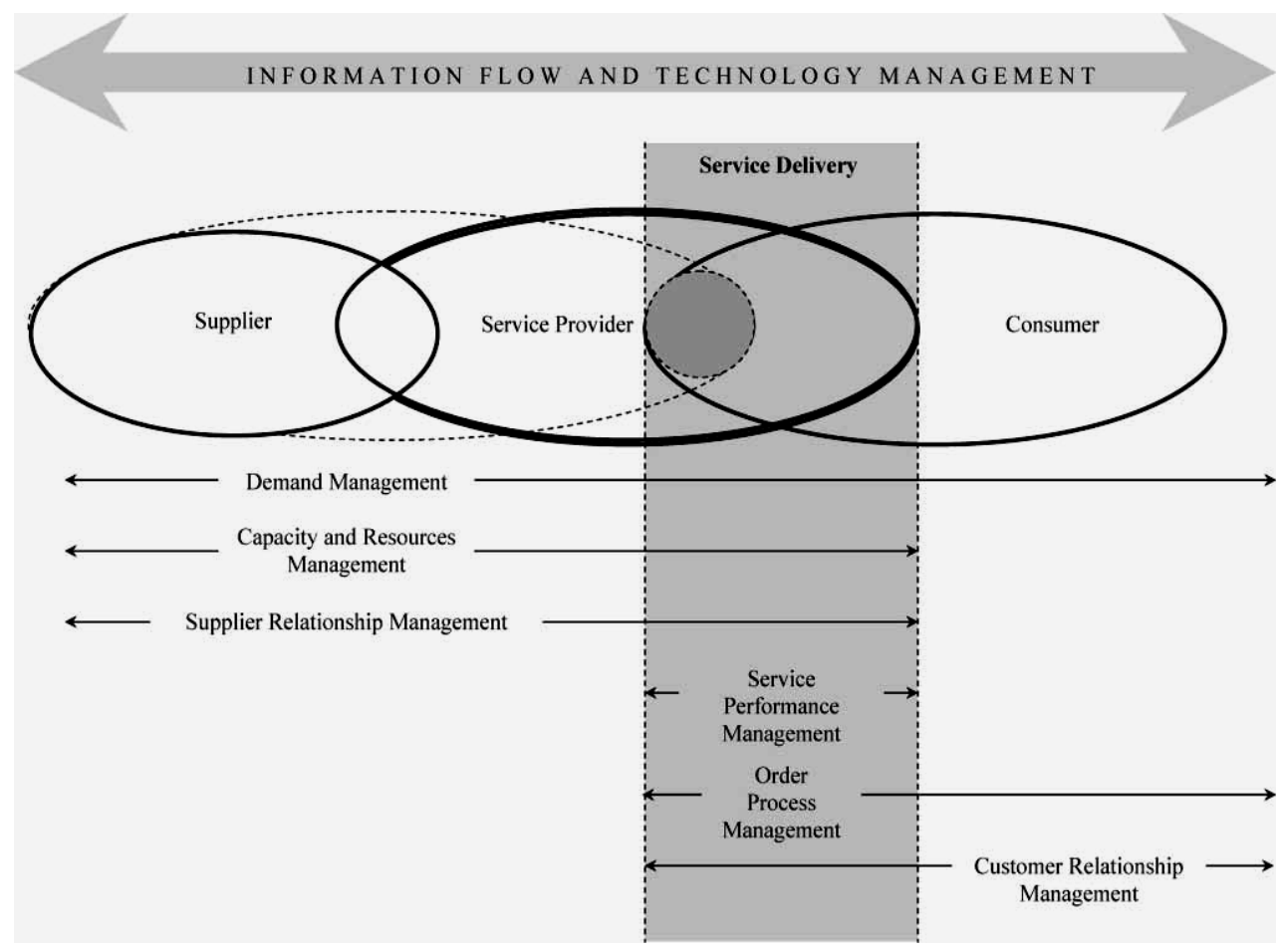

Figure 6. The IUE-SSC Model (Baltacioglu et al. 2007) 


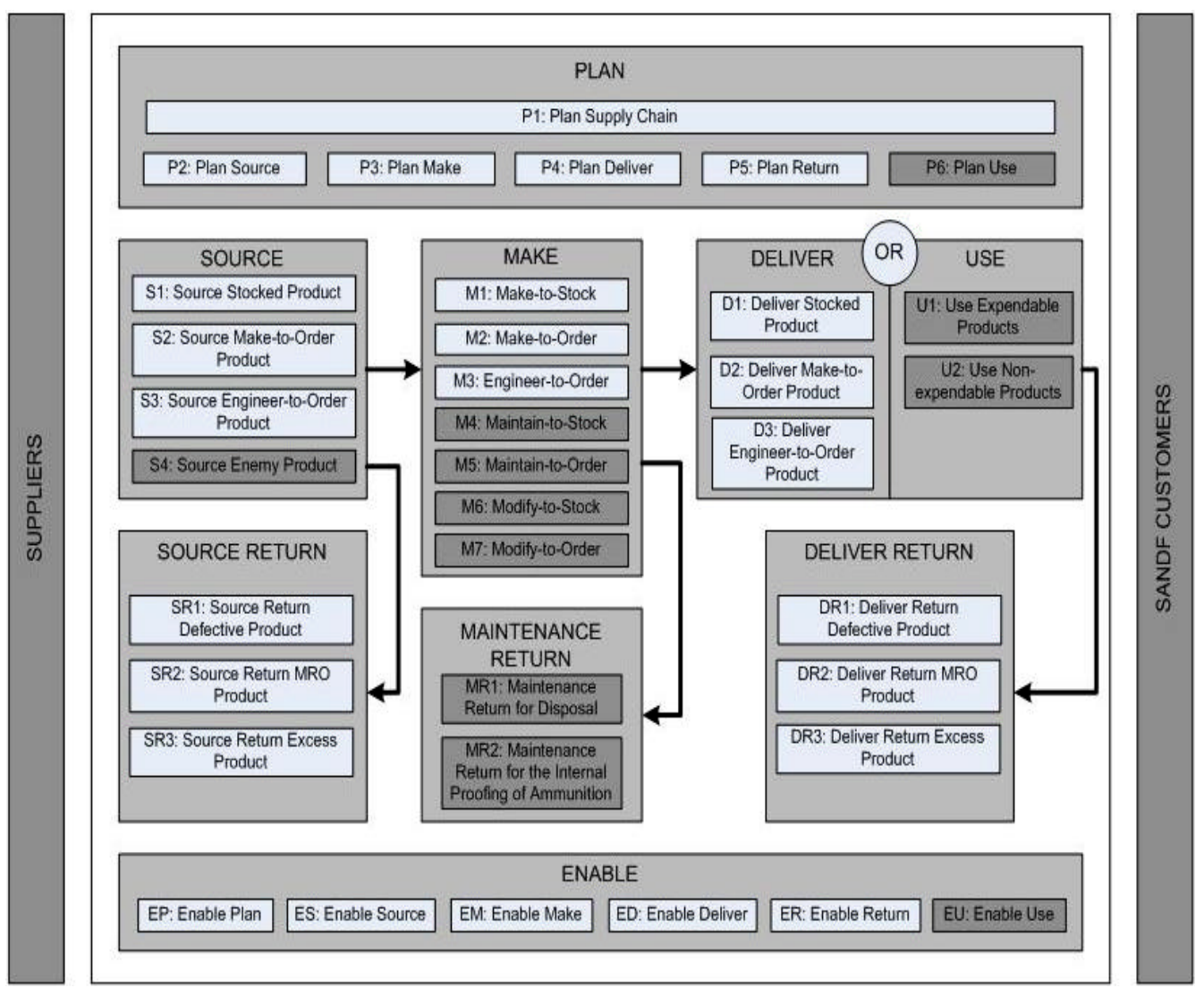

Figure 7. Adapted SCOR model for the military (Bean et al. 2009) 